\title{
Corrosion-Wear of ST60-Mn Steel in Cassava Juice
}

\author{
* M. A. Bodude, W.A. Ayoola , D. E. Esezobor and, A. A. Agbeleye \\ Department of Metallurgical and Materials Engineering, University of Lagos, Nigeria \\ *Corresponding Author: muideenbodude@yahoo.com
}

\begin{abstract}
Steels are used widely for production of machine components due to their versatility, low cost, ease of production and modification of their properties through heat-treatment. ST60Mn Steel is one of the common high strength steel produced in Nigeria and utilized for machine building purposes. Components made from this materials failed by wear, corrosion or both mechanism. The aim of this paper is to determine the influence of austempering heat-treatment on the corrosion-wear resistance of ST60Mn steel in cassava juice. The heat-treatment was performed by varying the austenitizing temperature, austempering temperature and time. The corrosion wear resistance was investigated under an instrumented pin-on-disc wear testing machine with the steel samples dipped in the cassava juice. The results obtained showed that the austempered ST60Mn steel has a wear rate of 3.0 $\mathrm{g} / \mathrm{cycle}$. While, the un-heat-treatment sample possess $70.1 \mu \mathrm{g} / \mathrm{cycle}$. This is a tremendous improvement in corrosion wear rate through the austempering heat treatment.
\end{abstract}

Keywords: Corrosion, wear, Austempering, Heat-treatment, Cassava-juice.

\section{INTRODUCTION}

ST60Mn Steel is a common medium carbon steel produced in Nigeria. It has strength comparable to those of imported machine building steels and is used for the production of components such as shafts, gears, bolts and nuts and other machine components that are subjected to rubbing actions in a corrosive medium as well as non-corrosive medium.

Greater abrasive resistance for low bainite matrix, with the same hardness, under a pin-on-disc test has been reported [1]. In recent time, heat treatment of steels with bainite structure ensures a good complex of mechanical properties has been observed [2]. Evidence showed that the 
ST60Mn steel reliability in these applications in terms of wear characteristic is lower than its imported counterparts [3].

The wear failures of steels depend on the intrinsic parameters such as chemical composition, microstructure, and smoothness of the mating surfaces as well as the extrinsic parameters like the applied load, sliding velocity, sliding distance or number of cycles. The failure also depends on the service environment such as the presence of corrosive agents. The presence of liquid or solid films on mating (rubbing) surfaces have marked influence on their wear rate has also be noted [4]. The simultaneous actions of corrosion and wear often lead to rapid deterioration of component. This is due to the continuous Mechanical removal of oxidized metal as a result of which a protective layer can not be sustained.

Machine components steels are required to have a bainite microstructure. The institution of Metallurgist [5] reported that an austempered bainitic steel consisting of two phase matrix of mixed bainitic ferrite and retained austenite superior wear resistance. The positive mechanical strength and corrosion resistance of bainite structure depend on number of factors such as bainite ferrite grain size, dislocation density, internal stress and carbide dispersion.

\section{MATERIAL AND METHODOLOGY}

The ST60Mn steel sample hot rolled $12 \mathrm{~mm}$ diameter rod used was obtained from Osogbo Steel rolling Mill, Osun State, Nigeria. The Steel has chemical composition: C(0.35-0.42), Si (0.200.30), Mn (0.90-1.20), P(0.04), CU(0.25), S(0.04), Cr(010).

Sixty-five test specimens of $14 \mathrm{~mm}$ length and $12 \mathrm{~mm}$ diameter were cut from the as-received steel samples. Five of the test specimens were retained as the as-received specimen while the rest were subjected to austempering heat-treatment under different austempering conditions. The steel specimens austempered using different austenitizing temperature TS(780, 820, 860 and 9000C), soaked for one hour, were quenched isothermally in salt bath containing 55\% KNO3 and 45\% NaNO3 at different transformation temperatures TT (340, 400, 480 and 5000C) and transformation times $\mathrm{tT}(1,15,45$ and 60 minutes). The samples were then air cooled to ambient temperature. Macro hardness test was conducted on the as-received and the austempered specimens using the Rockwell component of Briro V.A. (0-7300) universal hardness machine. The hardness values were read after a 1200 diamond cone indenter was pressed on the samples with a load of $1400 \mathrm{~N}$ for about 15 minutes. Prior to exposing samples to cassava juice, their weights were measured on PB 153 Meltler Toledo digital weighing balance.

The cassava juice which was used as a corrosive medium was obtained by pressing a freshly harvested and ground cassava tubers obtained from a research farm using a screw press with a bucket underneath to collect the cassava juice that was later preserved in a refrigerator. The $\mathrm{pH}$ 
of the freshly extracted cassava juice was determined before and after the corrosion wear test. The corrosion wear test was carried out by dipping the samples in the cassava juice inside the pin on disc wear rig and running the machine for 2000 cycles under an applied load of 500g. After each run (i.e. 2000 cycles) the sample was removed, washed, dried and weighed.

\section{RESULTS AND DISCUSSION}

Figure 1 illustrates the effect of different austenitizing temperatures on the wear-rate of ST60Mn steel solution quenched at $340^{\circ} \mathrm{C}$ at various quenching time. Generally, the figure shows that there is a decrease in the wear rate as the austentizing temperature increases from $780^{\circ} \mathrm{C}$ until at about $820^{\circ} \mathrm{C}$ and above when the wear rate increases with increasing austenitizing temperature. This behaviour may be attributed to formation of homogeneous austenite at $820^{\circ} \mathrm{C}$ and above. Conversely at below $820^{\circ} \mathrm{C}$ non-homogeneous austenite is formed. Transformation of nonhomogeneous austenite gives a mixture of pearlite and bainite while austenite at temperatures above $820^{\circ} \mathrm{C}$ attributes to formation of a low strength bainite due to grain growth effect hence, such structure possess high wear rate as shown in Figure 1.

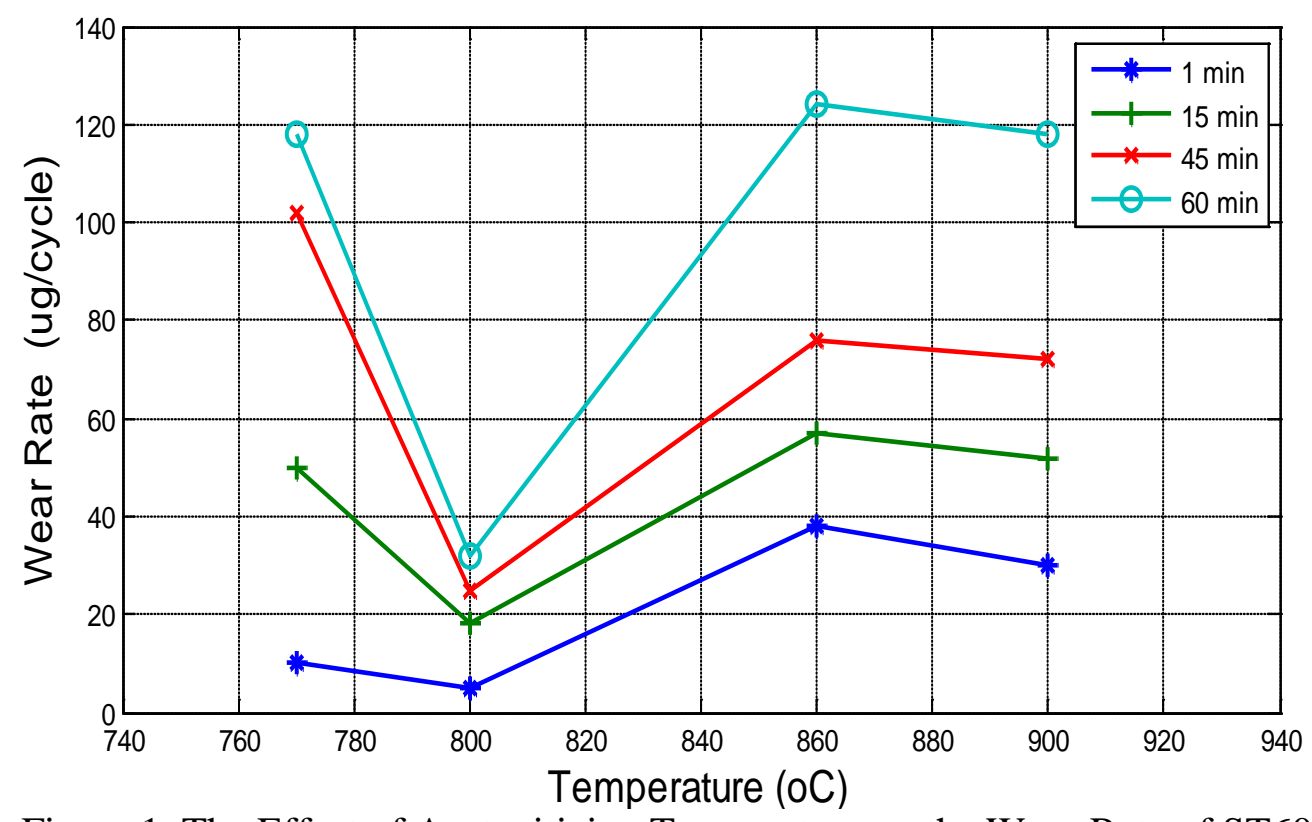

Figure 1. The Effect of Austenitizing Temperature on the Wear-Rate of ST60Mn Steel

Transformed at $340^{\circ} \mathrm{C}$ at various Intervals

Figure 2 depicts the effect of transformation temperature on the wear rate of ST60Mn steel which was earlier austenitized at $820^{\circ} \mathrm{C}$ and solution quenched at different temperatures and maintained at varying different time. It is evident from figure 2 that wears rate increases with increase in transformation temperature. 


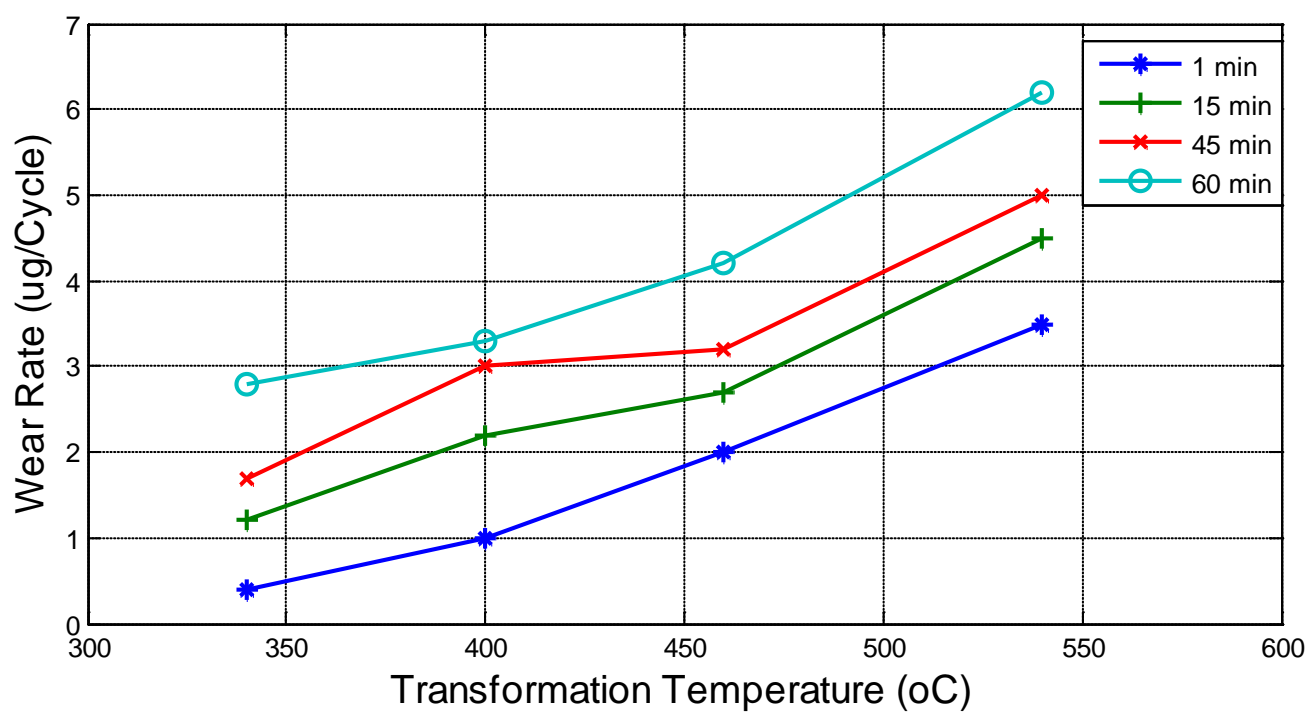

Figure 2. The Effect of Transformation Temperature on the Wear-Rate of ST60Mn Steel

Austenitized at $820^{\circ} \mathrm{C}$ at varying Time

Figure 3 shows the influence of transformation time on the wear rate of ST60Mn steel austenitized at different temperatures and transformed at $340^{\circ} \mathrm{C}$. Figure 3 shows that the wear rate increases with increase in transformation time. This behaviour may be linked to the fact that bainite formation involves carbon diffusion and ferrite shift type reactions which are time dependent.

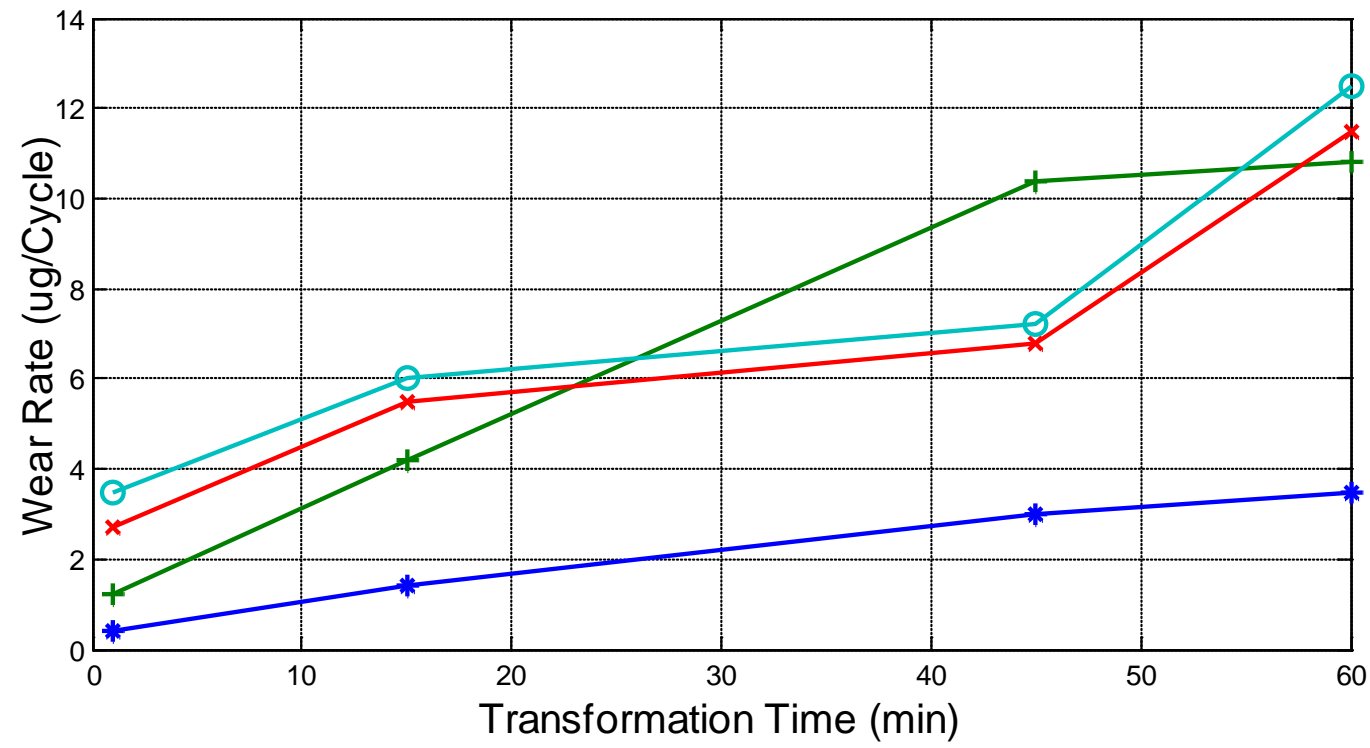

Figure 3. The Effect of Transformation on the Wear-Rate of ST60Mn Steel Austenitized at Different Temperature and transformed at $340^{\circ} \mathrm{C}$ 
Table 1 shows the hardness values of samples austenitized at $820^{\circ} \mathrm{C}$ and transformed at varying temperature and time. From the table it could be seen that austempering heat-treatment has positive impact on the hardness value of the steel when compared with that of the as received whose hardness value is $9.5 \mathrm{HRC}$.

TABLE 1. Hardness value of specimen austenitised at $820^{\circ} \mathrm{C}$

\begin{tabular}{|c|c|c|}
\hline $\begin{array}{c}\text { TRANSFORMATON } \\
\text { TEMPERATURE } \\
\text { T;C. }\end{array}$ & $\begin{array}{c}\text { TRANSFORMATION } \\
\text { TIME } \\
\text { TI. }\end{array}$ & $\begin{array}{c}\text { HARDNESS VALUE } \\
\text { HRC. }\end{array}$ \\
\hline 340 & 1 & 56.0 \\
\hline 340 & 15 & 53.5 \\
\hline 340 & 45 & 53.0 \\
\hline 340 & 60 & 51.0 \\
\hline 400 & 1 & 32.5 \\
\hline 400 & 15 & 31.0 \\
\hline 400 & 45 & 30.0 \\
\hline 400 & 60 & 28.0 \\
\hline 450 & 1 & 38.4 \\
\hline 450 & 15 & 38.2 \\
\hline 450 & 45 & 37.5 \\
\hline 450 & 60 & 34.5 \\
\hline 500 & 1 & 25.0 \\
\hline 500 & 15 & 24.0 \\
\hline 500 & 45 & 23.5 \\
\hline 500 & 60 & 21.3 \\
\hline
\end{tabular}

\section{CONCLUSION}

From the outcome of the analysis of results obtained on the ST60Mn steel, the following conclusions could be made.

1. Austempering heat-treatment is an effective technique for improving the corrosive wear resistance of ST60Mn steel.

2. Corrosion wear rate as well as hardness values are dependent on the austenitizing temperature , transformation temperature and time.

3 Austempering heat-treatment is capable of improving the structural integrity of ST60Mn steel in cassava juice 


\section{REFERENCES}

1. Zum-Gahr K. H., (1982): Relation between abrasive wear rate and the microstructure of metals, proceedings of the International Conference on wear of Materials, Reston.

2. Kaleten, A. Y; Lyzhkov, A. G. (2007): Alloying and heat treatment of steels with baintic structure. Metal Science and Heat-treatment. Vol. November 10 pp. 731 - 735.

3. Umorus, L.E.; A. O. Akinola and M. O. Adeoye (2006): Corrosion-wear. Journal of Applied Sciences Research Vol. 2. No. 9 pp. 529 - 532.

4. Williams, K. (2000): Plant Engineering Hardbook $2^{\text {nd }}$ ed. McGraw - Hill Book Copy pp. 5 44.

5. Institution of Metallurgists (1984): Development for future foundry property. The metallurgists and Materials Technologists, Vol. 16 No. 9 pp. 433. 